\title{
Work Engagement as Mediator between Perceived Participation, Supervisor Support and Altruistic Behaviors: Empirical Results from the Italian Social Enterprise Sector
}

Compromiso con el trabajo como mediador entre participación percibida, aporte de supervisor y comportamientos altruistas: resultados empíricos desde el sector italiano de empresas sociales

Recibido: marzo 30 de 2012 | Revisado: octubre 10 de 2012 | Aceptado: diciembre 26 de 2012

\author{
Juan Pablo Román Calderón * \\ Universidad EAFIT, Colombia \\ ADALGISA BATTISTELLI $* *$ \\ Université de Bordeaux, Bordeaux, France \\ CARLO ODOARDI *** \\ Università di Firenze, Italy
}

doi:10.11144/Javeriana.UPSY12-3.wemp

Para citar este artículo: Román, J. P., Battistelli, A., \& Odoardi, C. (2013). Work engagement as mediator between perceived participation, supervisor support and altruistic behaviors: Empirical results from the Italian social enterprise sector. Universitas Psychologica, 12(3), 899-909. doi:10.11144/Javeriana.UPSY12-3.wemp

Universidad EAFIT, Colombia. Researcher ID: H-6498-2013.E-mail: jromanca@eafit.edu.co

** Université de Bordeaux, Bordeaux, France. Laboratoire EPSYLON. Researcher ID: B-5059-2012. E-mail: adalgisa.battistelli@univ-montp3.fr

**** Università di Firenze, Italy. Dipartimento di Psicologia del Lavoro e delle Organizzazioni. E-mail: carlo.odoardi@unifi.it

\section{A B S T R A C T}

This research note presents an empirical study conducted in a number of social cooperatives (SCoops). Democratic governance has been identified as a defining aspect of this kind of social enterprise. Using the work and organizational psychology approach, the authors studied the effects of democratic governance and supervisor support on workers' engagement and organizational citizenship behaviors. The convenience sample technique was used for gathering the data. Data was collected with a self-administered questionnaire. The sample consisted of 258 participants from three different Scoops situated in northern Italy. Statistical analysis results suggest that worker's perceived participation and supervisor support enhance work engagement, and subsequently, altruistic behaviors. Finally, the authors comment on the limitations of the study giving methodological suggestions for future empirical research. Key words authors

Social enterprises, organizational citizenship behavior.

Key words plus

Organizational Psychology, Governance, Work, Quantitative Psychology.

\section{RESUMEN}

El presente artículo presenta una investigación realizada con la colaboración de varias cooperativas sociales (SCoops). El gobierno democrático es una de las principales características de este tipo de empresa social. A partir de la perspectiva de la psicología del trabajo y de las organizaciones (WOP), se estudiaron los efectos del gobierno democrático y del apoyo del superior sobre el compromiso hacia el trabajo y los comportamientos organizacionales de ciudadanía de los empleados. Se realizó un muestreo por conveniencia. Los datos fueron recogidos a través de un cuestionario autoadministrado. La muestra comprendió 258 empleados de tres SCoops situadas en el norte de Italia. Los análisis estadísticos realizados indican que la participación en la toma de decisiones y el apoyo del superior percibidos por los empleados, tienen una influencia positiva sobre su compromiso hacia el trabajo y sobre sus comportamientos altruistas. Por último, se presentan algunas sugerencias de carácter metodológico para la futura investigación. Palabras clave autores

Compromiso con el trabajo, comportamientos organizacionales de ciudadanía. 
Palabras clave descriptores

Psicología organizacional, governancia, trabajo, investigación cuantitativa.

\section{Introduction}

For almost two decades the Social Enterprise (SE) has captured the attention of scholars from all around the world. Globally, the SE has been defined as hybrid organizations that follow both social and economic goals (Austin, Stevenson, \& Wei-Skillern, 2006; Guzmán-Vásquez \& TrujilloDávila, 2008). Yet, the blurriness of the definition (Defourny \& Nyssens, 2009; Lyon \& Sepulveda, 2009; Neck, Brush, \& Allen, 2009) has led to continuous theoretical debates and divided research efforts. As a result, SE research may have unattended several managerial key issues. For instance, whereas in the U.S. social science researchers have a more managerial approach to social enterprise, in Europe researchers often draw on economic theory (Kerlin, 2006). As a result, empirical approaches to aspects such as SE human resources phenomena are still scarce. Paradoxically, the improvement of human resource management (HRM) practices has been identified for years as an imperative need (Peattie \& Morley, 2008; Thompson, 2002). In this sense, one of the few studies addressing this issue found that board members' HRM skills were undeveloped (Royce, 2007).

Now, given the importance that workers' involvement has in this kind of organization, this breach may seriously hinder SE's. Specifically, SE's are facing difficulties in areas such as recruitment and staff retention (Royce, 2007). This is not surprising given that SE's compete as employers in a labor market where competent resources are beckoned by competitive wages where for-profit organizations often offer more competitive wages. However, given that SE's are defined by a fundamental social mission (Alter, 2007), it is expected that SE's personnel is inspired by retributions that may complement the mere economic exchange (Mosca, Musella, \& Pastore, 2008; Tortia, 2009). Thus, understanding the sources of personnel motivation becomes a critical aspect of SE's (Austin et al., 2006). We contend that concerned disciplines such as work and organizational psychology (WOP) should lead to a better understanding on how aspects like managerial practices can affect personnel motivation. In doing this, research may clarify important managerial issues that may have passed unattended to the debate about general definitions of SE's.

In practice, the SE can adopt a range organizational structures that goes from social business, passing through cooperative enterprises, to traditional non-profits (Ridley-Duff \& Bull, 2011). Still, in all cases a participatory decision-making has been identified as a defining managerial practice of SE's (Galera \& Borzaga, 2009; Thompson, 2008). In this vein, Social Cooperatives (SCoops) can be thought as an exemplary type (International Cooperative Alliance, 2010; Mancino \& Thomas, 2005). This kind of SE is characterized by its pluralist and egalitarian principles (Ridley-Duff, 2007). SCoops have expanded globally and for some scholars these organizations constitute a promising research field (Ridley-Duff, 2008; Rindova, Barry, $\&$ Ketchen, 2009). According to Low (2006), cooperative enterprises are worth of being encouraged even in the U.S. In countries like Italy, SCoops have a long tradition of underpinning to a great extent the integration of disadvantaged people to the labor market and supplying social assistance services (Thomas, 2004). In particular, in a study that involved Latin American SE's, Alter (2007) notes how Italian SCoops have inspired a number of ventures abroad. This is not surprising given the exemplary role of cooperatives as agents of both economic development and social well-being. This fact was recently stressed by Ban Ki-moon (2012), general secretary of the United Nations.

Three SCoops from northern Italy participated in the research reported in this paper. This region is among the most economic developed areas in Europe. Along with southern Germany and the south of the UK, northern Italy has the highest GDP per inhabitant (Eurostat, 2010). The authors of this article believe that important lessons for Latin American SEs can be drawn from the long experience of Italian Scoops. In particular, these organi- 
Work Engagement as Mediator between Perceived Participation, Supervisor Support and Altruistic Behaviors

zations have a considerable experience on HRM (Thomas, 2004). Hence, a research on how HRM practices (i.e. participative decision-making) impact the attitudes and behaviors of employees of Italian Scoops can help to formalize and, subsequently, transfer the best practices of these organizations. Moreover, studies remarking the success of Scoops respectful of the cooperative principles can boost a different image of cooperative organizations. In countries like Colombia, where the cooperative sector has been used as an excuse for labor abuses, the latter is a further practical application of the research presented in this paper.

\section{A WOP Approach to the Consequences of Participatory Processes within Scoops}

Since participation in the decision-making is a defining aspect of SCoops, associated psychological processes may affect the relationship between employees and SCoops. Studies on the perception of workers on the degree in which participatory processes are enacted may complement extant economical studies on non-monetary remuneration (Mosca et al., 2008; Tortia, 2009). In WOP, the relationship between workers and organizations has been explained using different concepts. Work Engagement (WE), understood as a persistent and pervasive affective-cognitive work-related state that is not focused on a particular object, event or behavior (Schaufeli \& Bakker, 2004), is a helpful construct when trying to understand the employee's side in that relationship. Because of its wide scope, this concept seems useful when trying to understand the attitudes of workers regarding complex-diverse organizational contexts (i.e. SCoops). Regarding the conditions that would favor WE, Shaufeli and Bakker (2004) have suggested that WE is associated with participation in decision making. As regards its consequences, Bakker and Schaufeli (2008) have proposed that WE is associated with positive organizational outcomes, including extra-role behaviors (Schaufeli, Taris, \& Bakker, 2006).

Despite the classical debate on its characterization as an extra-role behavior (Organ, 1997), WOP researchers continued to pay attention to organizational citizenship behavior (OCB) (Dalal, 2005). More than concentrating in this debate, the authors of this article want to highlight the appropriateness of OCB as an outcome to be studied within SCo's. OCB refers to the "contributions to the maintenance and enhancement of the social and psychological context that supports task performance" (Organ, 1997, p. 91). Now, since OCB reinforces what is definitely an important asset to SCo's and at the same time regards conducts that have so much to do with cooperation (Smith, Organ, \& Near, 1983), these behaviors can be considered a suitable criterion variable in empirical research involving this type of SE.

Returning to the antecedents of WE, scholars have proposed that the lack of job resources is

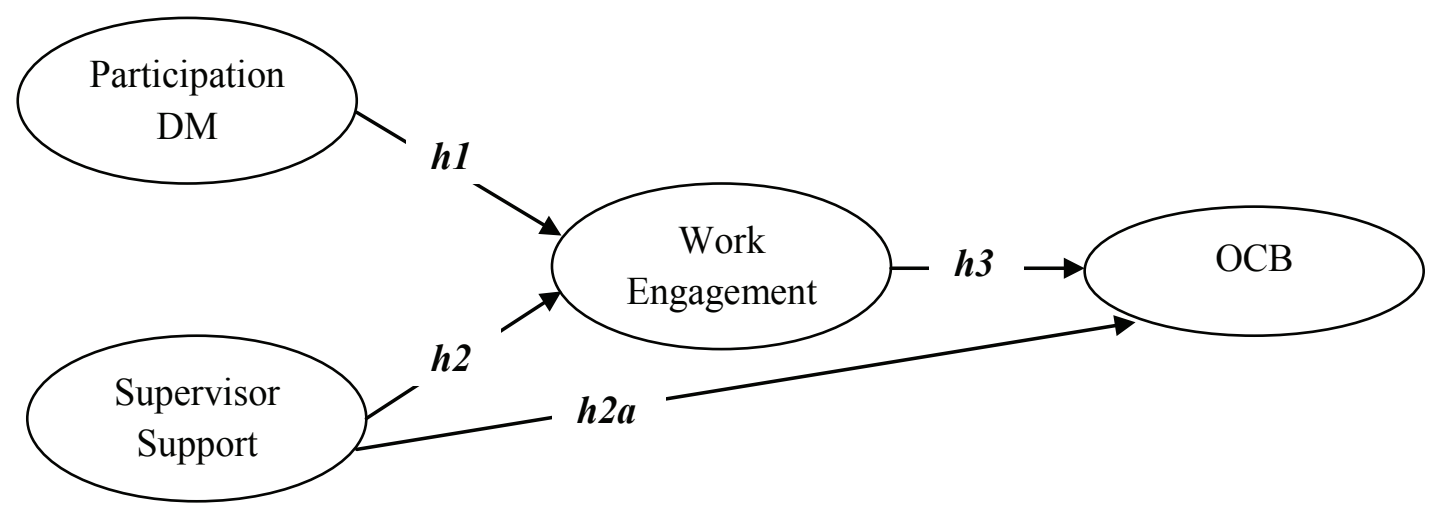

Figure 1. Hypothetical model Source: Own Work 
related to the employees' disengagement (Bakker \& Schaufeli, 2008; Shaufeli \& Bakker, 2004). In particular, Shaufeli and Bakker (2004) found that WE, to some extent intended as supervisory coaching, played a mediating role between available resource and positive organizational outcomes. In consequence, there are reasons to believe that WE would mediate -at least partially- the influence of support from the supervisor (PSS) on positive organizational outcomes. In fact, leader support is one of the predictors of $\mathrm{OCB}$, most often considered by OCB researchers (LePine, Erez, \& Johnson 2002).

From the assertions presented so far, a theoretical model was proposed (Figure 1). The model, in which WE mediates the effects of perceived PART and PSS on OCBa, is composed by the following hypothesis:

H1: Scoops employees' perceived that participation boosts their work engagement.

H2: Scoops employees' perceived that the supervisor support has a positive influence on their work engagement.

H2a: Scoops employees' perceived that the supervisor supports have a positive direct effect on altruistic behaviors.

H3: Scoops employees' work engagement boosts altruistic behaviors.

\section{Method}

\section{Sample}

Data for statistical analysis was obtained through a self-reported questionnaire. The participants participated voluntarily at the survey. The sample consisted of 251 subjects, including employees (36.3\%), partners (co-owners; 43.4\%) and administrative staff (20.3\%). The $54.6 \%$ of respondents were women, $92.8 \%$ had full-time, long term contracts while $4 \%$ of participants consisted of undergraduate students doing internships, $1.4 \%$ had full-time short term contracts and $1.4 \%$ was offering outsourcing services to the SCo's. Tenure ranged from 6 months to 32 years.

\section{Measures}

Previous research has suggested that SCo's actual levels of participation and democratic decisionmaking may differ from what is desired (RidleyDuff, 2009). As suggested before, the authors believe that an eventual divergence between principles attaining democratic governance and effective participation could influence negatively the work engagement. To assess actual participation on decision making (PART), a 3-item scale of a measure developed in Italy in a previous research was used (Román Calderón \& Battistelli, 2011). This measure showed satisfactory psychometric properties and the scale demonstrated good reliability $(\alpha=0.86)$ (Carmine \& Zeller, 1989). Respondents were asked to manifest their agreement with 3 statements concerning their perception about the degree of participation of members on decision-making processes. A 5 point Likert scale was used for each item.

The shortened version of the Utrecht Work Engagement Scale (UWES) was used to evaluate employees work engagement (WE) (Schaufeli \& Bakker, 2003). UWES was validated in Italy by Pisanti, Paplomatas, and Bertini (2008). According to Schaufeli and Bakker (2003) the shortened version of UWES is suitable to assess the general concept of engagement. This version was validated in Italy by Balducci, Fraccaroli, and Schaufeli (2010). It is worth mentioning that these characteristics of the shortened version were compatible with the data analysis. Like in the original scale, participants used a 7 point Likert scale to respond to the 9 items.

The Organizational Citizenship Behavior scale developed by Smith et al. (1983) has been widely used. Although the original dimensionality of this scale has been questioned, (LePine et al., 2002), some dimensions are used independently because of their strong linkage to organizational performance (Organ, Podsakoff, \& MacKenzie, 2006). Altruism, understood as helping behaviors such as assisting others with their works, merits special attention given the constitutive principles of SCo's. From the methodological point of view, a prior research has shown that the altruism dimension (OCBA) 
Work Engagement as Mediator between Perceived Participation, Supervisor Support and Altruistic Behaviors

can be treated as an independent factor (Snape \& Redman, 2010). OCBA has also been posited as an outcome of aspects like affective commitment (Organ \& Ryan, 1995). Some authors even suggest that OCBA may be best thought of as an indicator of OCB (LePine et al., 2002). The Smith et al. (1983) version of the OCBA sub-scale was used to assess altruist behaviors. It consists of 5 items scored on a 5 point Likert scale.

A three items version of the instrument of Eisenberger, Huntington, Hutchison, and Sowa (1986) was used to measure the perceived support from the supervisor (Eisenberger, Stinglhamber, Vandenbergh, Sucharski, \& Rhoades, 2002). The shortened version of Eisenberg et al. (1986) questionnaire was validated in Italy by Battistelli and Mariani (2011). The respondents answered to this instrument in a 5 point Likert scale.

\section{Analysis}

Smart PLS (versión 2.0 beta) statistical software was used for the data analysis (Ringle, Wende, $\&$ Will, 2005). Specifically, a structural equation modeling was carried out using the Partial Least Squares (PLS) methodology. As covariance-based SEM (CBSEM), PLS allows researchers to simultaneously analyze different complex relationships between latent variables (LVs). Furthermore, like CBSEM, PLS provides statistics on the psychometric properties of the measurement instruments. Compared with CBSEM, PLS is less restrictive in terms of sample-size (Haenlein \& Kaplan, 2004). Put it differently, PLS produces results to evaluate the structural and measurement models included in theoretical models including LVs. Moreover, PLS can be used in both exploratory and confirmatory studies and is particularly useful when consolidated theoretical models with new measures or novel relationships between LVs need to be tested (Chin, 2010). Given the newness of some of the measures and the small sample size obtained, PLS is particularly suitable to test our hypothetical model.

The evaluation of the PLS measurement model implies an analysis of the construct validity for all
LVs. To conclude about the convergent validity of the LVs, the researcher has to weigh the Average Variance Extracted (AVE) and the communality of the Observed Variables (OVs). The Composite Reliability (CR) index and Cronbach's Alpha $(\alpha)$ are habitually used to conclude on the reliability of the scales. In order to validate the measurement model its statistics need to overcome the following critical values: $\mathrm{AVE}>0.5$; communalities $>0.5$; $\mathrm{CR}>0.7$; $\alpha>0.6$ (Chin, 2010; Esposito Vinzi, Trinchera, \& Amato, 2010; Götz, Liehr-Gobbers, \& Krafft, 2010; Hair, Anderson, Tatham, \& Black, 2008).

The OVs' cross-loadings and the AVE test provide evidence on the divergent validity of the LVs. In PLS, OVs loadings on the expected LVs need to be up 0.7. Noteworthy, PLS algorithm tends to increase OVs' loadings to favor the analysis of the explained variance $\left(R^{2}\right)$ of the endogenous LVs. This is the reason for the presence in PLS measurement models of OVs cross-loadings exceeding the regular value of $>0.4$. However, the OVs cross-loadings cannot overcome the loading on the theoretical LV (Chin, 2010; Götz et al., 2010). The AVE test consists in comparing the square root of AVE with the construct correlations. When this value exceeds each pair of correlations, the LV's divergent validity can be concluded (Fornell \& Larcker, 1981).

The PLS structural model is examined weighting the endogenous LVs' $R^{2}$, the standardized regression coefficients $(\beta)$, the size effects of the predictors $\left(f^{2}\right)$, the statistical significance of each of the equations composing the model and the Stone-Geisser test $\left(Q^{2}\right)$. Regularly, two $Q^{2}$ statistics are used to evaluate the predictive validity of the PLS structural model: the cross-validated communality $\left(\mathrm{H}^{2}\right)$ for all LVs and the cross-validated redundancy $\left(F^{2}\right)$ for the endogenous $L V$ s. These two criteria reflect the possibility for the PLS model to predict the OVs (Götz et al., 2010). The following are the rules of thumb for the statistics of the PLS structural model: $R^{2}$ values of $0.67,0.33$, and 0.19 are described as substantial, moderate and weak (Chin, 1998). $f^{2}$ values of $0.02,0.15$ and 0.35 indicate small, medium, and large effects (Cohen, 1988). $H^{2}$ and $F^{2}$ values exceeding the zero support 
the predictive validity for the PLS structural model (Chin, 2010; Götz et al., 2010). The overall predictive performance of the model can be confirmed through the evaluation of the global criterion of goodness (GoF index) (Tenenhaus, Amato, \& Esposito, 2004). GoF values of $0.1,0.25$ and 0.36 correspond to low, medium and high model predictive capability (Wetzels, Odekerken-Schröder, \& van Oppen, 2009).

Since PLS SEM does not provide goodness of fit indexes allowing comparing between competitive models, an alternative procedure was adopted to this end. An additional path was added to the original model in order to test another PLS model. To decide between the two models, both the significance and the effects on LV' R2 of the additional path were weighted.

Finally, the retained model was controlled for several demographic and organizational variables. Thus, in addition to the paths composing the re- tained model, the dependent variable was regressed on age, gender, tenure and type of affiliation.

\section{Results}

Overall, the findings regarding the PLS measurement model were satisfactory. According to the results of the statistical data-analysis construct validity could be concluded for that all the LV's. Aside from the item we9, all OV acceptably loaded on the corresponding constructs $(>0.7)$ without cross-loadings on the remaining LVs (see Table 1). Since the cross-loadings of we 9 did not surpass the hypothesized loadings, and in order to preserve the high of the criterion variable, the item was maintained. This decision was supported by further results on the construct validity of all LVs.

The divergent validity of all LVs was confirmed by the results of the AVE test (see Table 2). The

TABLE 1

Cross Loadings PLS Measurement Model

\begin{tabular}{lcccc}
\hline & OCBa & PART & PSS & WE \\
\hline ocb1 & 0.82 & 0.46 & 0.47 & 0.6 \\
ocb2 & 0.72 & 0.15 & 0.36 & 0.41 \\
ocb3 & 0.88 & 0.55 & 0.54 & 0.62 \\
ocb4 & 0.89 & 0.42 & 0.52 & 0.68 \\
ocb5 & 0.86 & 0.49 & 0.58 & 0.66 \\
part1 & 0.42 & 0.93 & 0.68 & 0.48 \\
part2 & 0.47 & 0.94 & 0.65 & 0.47 \\
part3 & 0.53 & 0.93 & 0.64 & 0.67 \\
pss1 & 0.53 & 0.86 & 0.53 \\
pss2 & 0.52 & 0.64 & 0.88 & 0.53 \\
pss3 & 0.54 & 0.67 & 0.88 & 0.61 \\
we1 & 0.52 & 0.45 & 0.58 & 0.9 \\
we2 & 0.59 & 0.57 & 0.9 \\
we3 & 0.68 & 0.55 & 0.55 & 0.89 \\
we4 & 0.62 & 0.54 & 0.55 & 0.88 \\
we5 & 0.58 & 0.49 & 0.47 & 0.86 \\
we6 & 0.53 & 0.41 & 0.52 & 0.71 \\
we7 & 0.52 & 0.49 & 0.56 & 0.87 \\
we8 & 0.53 & 0.49 & 0.51 & 0.83 \\
we9 & 0.65 & 0.51 &
\end{tabular}

Source: Own work. 
Work Engagement as Mediator between Perceived Participation, Supervisor Support and Altruistic Behaviors

TABLE 2

Lvs' Correlations, Reliability and Construct Validity Indexes

\begin{tabular}{lccccccc}
\hline & 1 & 2 & 3 & 4 & CRa & $\alpha b$ & AVEc \\
\hline 1. OCBa & $0.83^{*}$ & & & & 0.92 & 0.89 & 0.7 \\
2. PART & 0.52 & 0.93 & & & 0.95 & 0.92 & 0.87 \\
3. PSS & 0.6 & 0.71 & 0.87 & & 0.91 & 0.85 & 0.76 \\
4. WE & 0.72 & 0.6 & 0.64 & 0.85 & 0.96 & 0.95 & 0.72 \\
\hline
\end{tabular}

Note. $N=258$. a Composite Reliability. b Cronbach's Alfa. c Average Variance Extracted (AVE). * Squared root of AVE. AVE Test (Fornell \& Larcker, 1981).

Source: Own work.

TABLE 3

Lvs' Explained Variance, Communalities and Redundancies

\begin{tabular}{lccccc}
\hline \multicolumn{1}{c}{ Variable } & $\mathrm{R}^{2}$ & Communality & $\mathrm{H}^{2}$ & Redundancy & $\mathrm{F}^{2}$ \\
\hline 1. OCBa & 0.56 & 0.7 & 0.7 & 0.16 & 0.35 \\
2. PART & & 0.87 & 0.76 & & \\
3. PSS & & 0.76 & 0.87 & & 0.18 \\
4. WE & 0.45 & 0.72 & 0.72 & & \\
\hline Average & 0.5 & 0.76 & & & \\
GoF* & 0.62 & & & & \\
\hline
\end{tabular}

Note. $N=258 . *$ Global criterion of goodness.

Source: Own work.

TABLE 4

PLS Structural Model

\begin{tabular}{lcccc}
\hline \multicolumn{1}{c}{ Paths } & $\beta$ & t-value & f2 & Ratings \\
\hline PART $\rightarrow$ WE & 0.28 & $4.19^{*}$ & 0.07 & Small to medium \\
PSS $\rightarrow$ WE & 0.44 & $6.18^{*}$ & 0.18 & Medium to large \\
WE $\rightarrow$ OCBa & 0.57 & $10.67^{*}$ & 0.29 & Medium to large \\
PSS $\rightarrow$ OCBa & 0.24 & $4^{*}$ & 0.07 & Small to medium \\
\hline
\end{tabular}

Note. $N=258$. Bootstrapping 1000 samples.

$* p<0.001$.

Source: Own work.

values of the AVE test for each construct exceeded all pair correlations. The reliability of the measures is presented in Table 2. In all cases, $\alpha$ surpassed the critical value $(>0.6)$. Likewise, the CRs of all $\mathrm{LVs}$ went above the rule of thumb $(>0.8)$. As regards the convergent validity of the constructs, all values were satisfactory $(>0.5)$. Moreover, as shown later in table 3 , the communalities overcame the critical value $(>0.5)$.

Similarly, the results for the PLS structural model were satisfactory (see Table 3 ). The different values obtained by the PLS model support its predictive validity. In particular, medium $R^{2}$ values were found for both the mediator (WE) and the criterion variable $(\mathrm{OCBa})$. Furthermore, the $\mathrm{H}^{2}$ and $F^{2}$ results $(>0)$ confirmed the high predictive validity indicated by the GoF index. Hence, in general, the statistical analysis supports all the hypothesis of the study.

Table 4 shows more specific results for each of the 4 hypotheses that constituted the theoretical model. As reflected by the $t$-values of each path (> 2.96), all the hypothesized relationships between the LVs were significant at the $p<0.001$ 
level. The $\beta$ and the size effects ratings reflect that whereas PSS exerted a more important influence over WE than PART, the stronger effect among the hypothesized relationships is the one of the mediator on the criterion variable. The meaning of these two results will be commented later in the discussion section.

Next, one path was added to the theoretical model in order to and additional -partial- mediation model. Specifically, OCBa was sequentially regressed on PART. As a result of a relatively weaker influence $(\beta=0.02, t=3.1)$ and no added explained variance, the hypothesized model was retained as the model that fitted better the data.

With regard to the control variables, no significant influence was found on OCBa. All the additional paths connecting each one of the control variables to OCBa resulted non-significant ( $p$ $<0.05)$. That is to say that OCBa did not depend on age, gender, tenure and type of affiliation to the organization. Noteworthy, the latter suggest that OCBa is independent of the fact that Scoops respondents were co-owners, employees or administrative staff.

\section{Discussion}

The empirical findings of the research suggest that participation in decision-making and perceived support from the supervisor have both a positive influence on altruistic behaviors. The role that work engagement has in these relationships confirms prior WOP research results. On the one hand, the findings of the research corroborate that democratic governance is of great importance for Scoops' employees. The fact that Scoops employees are engaged and respond with altruistic behaviors when they perceive that democratic principles are enacted is an empirical confirmation of the assumption, according to which people working in social enterprises are value-driven (Austin et al., 2006; Weerawardena \& Sullivan-Mort, 2006). Noteworthy, according to our research results, the perceived support from the supervisor appeared to have a stronger influence on both employees' work engagement and on altruistic behaviors. This is not surprising since support from the supervisor can be intended as an indicator of organizational support (Eisenberger et al., 1986; Hutchison, 1997). Certainly, cooperative organizations are commonly perceived as supporting enterprises where helping and collaborative behaviors have place.

As Scoops possess characteristics of both nonprofit and for-profit organizations, the study presented up-to-here should be replicated by future research in each sector. For instance, it could be that within for-profit organizations democratic decision-making and supervisor support boost workers work engagement and, subsequently, further cooperative behaviors directed to the organization. Noteworthy, citizenship behaviors seem to favor task performance in for-profit organizations (Organ, 1997). Therefore, conversely to mainstream SE theory and practice tend to endorse HRM models extracted from the for-profit sector (Austin et al., 2006; Peattie \& Morley, 2008), validating this research model in for-profit organizations would suggest that lessons for for-profit managerial practices could be drawn from the SE sector.

Notwithstanding these results, this study has certain methodological limitations. First, using only self-report measures can enlarge the variance explained by a given model. In fact, some authors have warned about this problem in studies having $\mathrm{OCB}$ as a criterion variable (Podsakoff, MacKenzie, Paine, \& Bachrach, 2000). Secondly, further longitudinal studies would better support our specifications about directionality among variables. Future empirical research should also relate additional variables to perceived participation as predictors of the relationship between workers of SCo's and the organizations. For instance, Ridley-Duff (2007) suggested that along surplus sharing democratic debate might produce emotional commitment of workers of SE's. Given the importance that social mission has in this kind of organization, perceptions of workers on the degree in which organizational goals are reach may account for other psychological aspects determining the motivation of workers of SCo's. 


\section{Work Engagement as Mediator between Perceived Participation, Supervisor Support and Altruistic Behaviors}

\section{References}

Alter, K. (2007). Social enterprise typology. Wilmington, DE: Virtue Ventures LLC. Available at www.virtueventures.com/setypology.pdf

Austin, J., Stevenson, H., \& Wei-Skillern, J. (2006). Social and commercial entrepreneurship: Same, different, or both? Entrepreneurship Theory and Practice, 30(1), 1-22.

Balducci, C., Fraccaroli, F., \& Schaufeli, W. B. (2010). Psychometric properties of the Italian version of the Utrecht Work Engagement Scale (UWES-9). European Journal of Psychological Assessment, 26(2), $143-149$

Bakker, A., \& Schaufeli, W. (2008). Positive organizational behavior: Engaged employees in flourishing organizations. Journal of Organizational Behavior, 29(2), 147-154.

Battistelli, A., \& Mariani, M. G. (2011). Supporto organizzativo: validazione della versione italiana della survey of perceived organizational support (versione a 8 item). Giornale Italiano di Psicologia, 38(1), 189-211.

Carmine, E., \& Zeller, R. (1989). Reliability and validity assessment. London: Sage.

Chin, W. W. (1998). The partial least squares approach to structural equation modeling. In G. A. Marcoulides (Ed.), Modern methods for business research (pp. 295-358). Mahwah, NJ: Erlbaum.

Chin, W. W. (2010). How to write up and report PLS analyses. In V. Esposito Vinzi, W. W. Chin, J. Henseler \& H. Wang (Eds.), Handbook of partial least squares (pp. 655-690). Berlin: Springer-Verlag.

Cohen, J. (1988). Statistical power analysis for the behavioral sciences. Hillsdale, NJ: Erlbaum.

Götz, O., Liehr-Gobbers, K., \& Krafft, M. (2010). Evaluation of structural equation models using the Partial Least Squares (PLS) approach. In V. Esposito Vinzi, W. W. Chin, J. Henseler \& H. Wang (Eds.), Handbook of partial least squares (pp. 691-711). Berlin: Springer-Verlag.

Dalal, R. (2005). A meta-analysis of the relationship between organizational citizenship behavior and counterproductive work behavior. Journal of Applied Psychology, 90(6), 1241-1255.
Defourny, J., \& Nyssens, M. (2009, July). Conceptions of social enterprise and social entrepreneurship in Europe and the United States: Convergences and divergences. Second EMES International Conference on Social Enterprise, University of Trento, Italy.

Eisenberger, R., Hungtington, R., Hutchison, S., \& Sowa, D. (1986). Perceived organizational support. Journal of Applied Psychology, 71(3), 500-507.

Eisenberger, R., Stinglhamber, F., Vandenberghe, C., Sucharski, I. L., \& Rhoades, L. (2002). Perceived supervisor support: Contributions to perceived organizational support and employee retention. Journal of Applied Psychology, 87(3), 565-573.

Esposito Vinzi, V., Trinchera, L., \& Amato, S. (2010). PLS path modeling: From foundations to recent developments and open issues for model assessment and improvement. In V. Esposito Vinzi, W.W. Chin, J. Henseler \& H. Wang (Eds.), Handbook of partial least squares (pp. 47-82). Berlin: SpringerVerlag.

Eurostat. (2010). Eurostat regional yearbook 2010. Available at http://epp.eurostat.ec.europa.eu/cache/ ITY_OFFPUB/KS-HA-10-001/EN/KS-HA-10. 001-EN.PDF

Fornell, C., \& Larcker, D. F. (1981). Evaluating structural equation models with unobserved variables and measurement error. Journal of Marketing Research, 18(1), 39-50.

Galera, G., \& Borzaga, C. (2009). Social enterprise: An international overview of its conceptual evolution and legal implementation. Social Enterprise Journal, 5(3), 210-228.

Guzmán-Vásquez, A., \& Trujillo-Dávila, M. A. (2008). Emprendimiento social: revisión de literatura. Estudios Gerenciales, 24(109), 105-125.

Haenlein, M. A., \& Kaplan, A. M. (2004). A beginner's guide to partial least squares analysis. Understanding Statistics, 3(4), 283-297.

Hair, J., Anderson, R., Tatham, R., \& Black, W. (2008). Análisis multivariante. Madrid: Prentice Hall.

Hutchison, S. (1997). A path model of perceived organizational support. Journal of Social Behavior and Personality, 12(1), 159-174.

International Co-operative Alliance. (2010). Statement on the co-operative identity: Co-operative values and 
principles. Available at http://www.ica.coop/coop/ principles.html

Kerlin, J. (2006). Social enterprise in the United States and Europe: Understanding and learning from the differences. Voluntas, 17(3), 247-263.

Ki-moon, B. (2011). 2012 Año internacional de las cooperativas. Available at http://www.un.org/en/events/ coopsyear/

LePine, J., Erez, A., \& Johnson, D. E. (2002). The nature and dimensionality of organizational citizenship behavior: A critical review and meta-analysis. Journal of Applied Psychology, 87(1), 52-65.

Low, C. (2006). A framework for the governance of social enterprise. International Journal of Social Economics, 33(5-6), 376-385.

Lyon, F., \& Sepulveda, L. (2009). Mapping social enterprises: Past approaches, challenges and future directions. Social Enterprise Journal, 5(1), 83-94.

Mancino, A., \& Thomas, A. (2005). An Italian pattern of social enterprise: The Social Cooperative. Nonprofit Management $\mathscr{E}$ Leadership, 15(3), 357-369.

Mosca, M., Musella, M., \& Pastore, F. (2008). Relational goods, monitoring and non-pecuniary compensations in the nonprofit sector: The case of the Italian social services. Annals of Public and Cooperative Economics, 78(1), 57-86.

Neck, H., Brush, C., \& Allen, E. (2009). The landscape of social entrepreneurship. Business Horizons, 52(1), 13-19.

Organ, D. W. (1997). Organizational citizenship behavior: It's construct clean-up time. Human Performance, 10(2), 85-97.

Organ, D. W., Podsakoff, P. M., \& MacKenzie, S. B. (2006). Organizational citizenship behavior: Its Nature, antecedents, and consequences. Thousand Oaks, CA: Sage.

Organ, D. W., \& Ryan, K. (1995). A meta-analytic review of attitudinal and dispositional predictors of organizational citizenship behavior. Personnel Psychology, 48(4), 775-802.

Peattie, K., \& Morley, A. (2008). Eight paradoxes of the social enterprise research agenda. Social Enterprise Journal, 4(2), 91-107.

Pisanti, R., Paplomatas, A., \& Bertini, M. (2008). Measuring the positive dimensions among health care workers: A contribution to the Italian validation of the UWES-Utrecht Work Engagement Scale. Giornale Italiano di Medicina del Lavoro ed Ergonomia, 30(1), 11-119.

Podsakoff, P., MacKenzie, S., Paine, J., \& Bachrach, D. (2000). Organizational citizenship behaviors: A critical review of the theoretical and empirical literature and suggestions for future research. Journal of Management, 26(3), 513-563.

Rindova, V., Barry, D., \& Ketchen, J. (2009). Entrepreneuring as emancipation. Academy of Management Review, 34(3), 477-491.

Ridley-Duff, R. (2007). Communitarian perspectives on social enterprise. Corporate Governance, 15(2), 382-392.

Ridley-Duff, R. (2008). Social enterprise as a socially rational business. International Journal of Entrepreneurial Behaviour Eु Research, 14(5), 292-312.

Ridley-Duff, R. (2009). Co-operative social enterprises: Company rules, access to finance and management practice. Social Enterprise Journal, 5(1), 50-68.

Ridley-Duff, R., \& Bull, M. (2011). Understanding social enterprise: Theory and practice. London: Sage.

Ringle, C. M., Wende, S., \& Will, A. (2005). SmartPLS. Hamburg: SmartPLS.

Román-Calderón, J. P., \& Battistelli, A. (2011). Organizational goals and participation within social enterprises: An exploratory study and development of two new measures. Risorsa Uomo, 16(3), 296-307.

Royce, M. (2007). Using human resource management tools to support social enterprise: Emerging themes from the sector. Social Enterprise Journal, 3(1), 10-19.

Schaufeli, W. B., \& Bakker, A. B. (2003). UWES-Utrecht Work Engagement Scale: Test manual. Unpublished manuscript, Department of Psychology, Utrecht University, The Netherlands.

Schaufeli, W. B., \& Bakker, A. B. (2004). Job demands, job resources, and their relationship with burnout and engagement: A multi-sample study. Journal of Organizational Behavior, 25(3), 293-315.

Schaufeli, W. B., Taris, T. W., \& Bakker, A. B. (2006). Dr. Jekyll and Mr. Hide: On the differences between work engagement and workaholism. In R. Burke (Ed.), Work hours and work addiction (pp. 193-252). Northhampton, UK: Edward Elgar. 


\section{Work Engagement as Mediator between Perceived Participation, Supervisor Support and Altruistic Behaviors}

Smith, C. A., Organ, D. W., \& Near, J. P. (1983). Organizational citizenship behavior: Its nature and antecedents. Journal of Applied Psychology, 68(4), 653-663.

Snape, E., \& Redman, T. (2010). HRM Practices, organizational citizenship behavior, and performance: A multi-level analysis. Journal of Management Studies, 47(7), 1219-1247.

Tenenhaus, M., Amato, S., \& Esposito Vinzi, V. (2004). A global goodness-of-fit index for PLS structural equation modeling. Proceedings of the XLII SIS Scientific Meeting (pp. 739-742). Padova: CLEUP.

Thomas, A. (2004). The rise of social cooperatives in Italy. International Journal of Voluntary and Nonprofit Organizations, 15(3), 243-263.

Thompson, J. (2002). The world of the social entrepreneur. The International Journal of Public Sector Management, 15(5), 412-431.
Thompson, J. (2008). Social enterprise and social entrepreneurship: Where have we reached? Social Enterprise Journal, 4(2), 412-431.

Tortia, E. (2009). Perceived fairness and worker wellbeing in public, for-profit and nonprofit firms: Evidence from the Italian social service sector. In S. Destefanis \& M. Mussella (Eds.), Paid and unpaid labour in the social economy (pp. 97-114). Heidelberg: Physica-Verlag HD.

Weerawardena, J., \& Sullivan-Mort, G. (2006). Investigating social entrepreneurship: A multidimensional model. Journal of World Business, 41(1), 21-35.

Wetzels, M., Odekerken-Schröder, G., \& van Oppen, C. (2009). Using PLS path modeling for assessing hierachical construct models: Guidelines and empirical illustration. MIS Quarterly, 33(1), 177-195. 
